\title{
A global model simulation for 3-D radiative transfer impact on surface hydrology over the Sierra Nevada and Rocky Mountains
}

\author{
W.-L. Lee ${ }^{1}$, Y. Gu ${ }^{2}$, K. N. Liou ${ }^{2}$, L. R. Leung ${ }^{3}$, and H.-H. Hsu ${ }^{1}$ \\ ${ }^{1}$ Research Center for Environmental Changes, Academia Sinica, Taipei, Taiwan \\ ${ }^{2}$ Joint Institute for Regional Earth System Science and Engineering, Department of Atmospheric and Oceanic Sciences, \\ University of California, Los Angeles, CA 90095, USA \\ ${ }^{3}$ Pacific Northwest National Laboratory, Richland, WA 99352, USA \\ Correspondence to: Y. Gu (gu@atmos.ucla.edu)
}

Received: 4 September 2014 - Published in Atmos. Chem. Phys. Discuss.: 15 December 2014

Revised: 18 April 2015 - Accepted: 21 April 2015 - Published: 19 May 2015

\begin{abstract}
We investigate 3-D mountain effects on solar flux distributions and their impact on surface hydrology over the western United States, specifically the Rocky Mountains and the Sierra Nevada, using the global CCSM4 (Community Climate System Model version 4; Community Atmosphere Model/Community Land Model - CAM4/CLM4) with a $0.23^{\circ} \times 0.31^{\circ}$ resolution for simulations over 6 years. In a 3-D radiative transfer parameterization, we have updated surface topography data from a resolution of $1 \mathrm{~km}$ to $90 \mathrm{~m}$ to improve parameterization accuracy. In addition, we have also modified the upward-flux deviation (3-D-PP (planeparallel)) adjustment to ensure that the energy balance at the surface is conserved in global climate simulations based on 3 -D radiation parameterization. We show that deviations in the net surface fluxes are not only affected by 3-D mountains but also influenced by feedbacks of cloud and snow in association with the long-term simulations. Deviations in sensible heat and surface temperature generally follow the patterns of net surface solar flux. The monthly snow water equivalent (SWE) deviations show an increase in lower elevations due to reduced snowmelt, leading to a reduction in cumulative runoff. Over higher-elevation areas, negative SWE deviations are found because of increased solar radiation available at the surface. Simulated precipitation increases for lower elevations, while it decreases for higher elevations, with a minimum in April. Liquid runoff significantly decreases at higher elevations after April due to reduced SWE and precipitation.
\end{abstract}

\section{Introduction}

Orographic forcing is an efficient and dominant mechanism for harnessing water vapor into consumable freshwater in the form of precipitation, snowpack, and runoff. It has been estimated that about $60-90 \%$ of water resources originate from mountains worldwide. Mountain water resources not only support human activities but are also vital to diverse terrestrial and aquatic ecosystems. There is strong observational evidence that mountain water resources have been and continue to be threatened by global warming trends, which lead to snowpack reduction (Mote et al., 2007; Kapnick and Hall, 2012) and alter the timing and amount of runoff (McCabe and Clark, 2005). Observations and modeling studies have suggested that warming trends are amplified in mountains compared to lowlands because of the moist adiabatic structure of the atmosphere - the lapse-rate effect and snowalbedo feedback (Leung et al., 2004). Also, mountains are an integral part of global monsoon systems, in which elevated warming may have an important influence on monsoon circulation and the associated water cycle. However, accurate predictions of mountain snowpack have been limited by uncertainty in projecting future changes in temperature and precipitation due to model limitations in representing snow processes and their interactions with radiative transfer and other terrestrial processes in mountain environments.

The spatial and temporal distributions of surface solar radiation are the primary energy sources that contribute to the energy and water balance on 3-D and inhomogeneous mountain surfaces, with a particularly strong influence on 
snowmelt processes (Geiger, 1965; Bonan, 2002; Gu et al., 2002; Müller and Scherer, 2005). The spatial orientation and inhomogeneous features of mountains and snow that interact with direct and diffuse solar beams are intricate and complex. Quantifying the interactions of direct and diffuse solar beams with mountain topography and reliably determining total surface solar fluxes for incorporation in a land surface model has been a challenging task that has yet to be accomplished in regional and high-resolution global climate modeling. Essentially all modern climate models have used a plane-parallel (PP) radiative transfer program in performing radiation parameterization; however, the potential errors have never been quantified.

In conjunction with radiative transfer in mountains and snow regions, we have developed a Monte Carlo photon tracing program specifically applicable to intense and intricate inhomogeneous mountains and demonstrated that the effect of mountains on the surface radiative balance is substantial in terms of subgrid variability as well as domain average conditions (Liou et al., 2007; Lee et al., 2011, 2013). Because of the computational burden required by the 3-D Monte Carlo photon tracing program, an innovative parameterization approach has been developed in terms of deviations from PP radiative transfer results readily available in climate models for the five component of surface solar flux: direct and diffuse fluxes, direct and diffuse reflected fluxes, and coupled mountain-mountain flux (Lee et al., 2011). We have derived five regression equations for flux deviations, which are linear and have a general $5 \times 5$ matrix form, and have successfully incorporated this efficient parameterization into the Weather Research Forecasting (WRF) model, which was used as the test bed in connection with the Fu-Liou-Gu PP radiation scheme (Fu and Liou, 1992, 1993; Gu et al., 2010, 2011) that has been included in the WRF physics package. We have investigated the 3-D mountain and snow effect on solar flux distributions and the latter impact on surface hydrology over the western United States, specifically the Rocky Mountains and the Sierra Nevada, using the WRF applied at a $30 \mathrm{~km}$ grid resolution (Gu et al., 2012; Liou et al., 2013)

More recently, the 3-D radiative transfer parameterization has been incorporated into the global Community Climate System Model version $4(\mathrm{CCSM} 4)$ with a $0.23^{\circ} \times 0.31^{\circ}$ resolution to investigate the long-term 3 -D effect on the simulated surface solar insolation patterns and associated sensible and latent heat fluxes, surface temperature, and surface hydrology over mountains and snow in the western United States, covering both the narrow coastal Sierra Nevada and the broad continental Rocky Mountains. Marked by complex terrain and with a surface hydrology dominated by seasonal precipitation and snow accumulation and snowmelt (e.g., Leung et al., 2003a, b), the surface hydrology of the western United States has been shown to be extremely sensitive to climate change (Leung et al., 2004; Kapnick and Hall, 2010). Thus, understanding factors leading to uncertainties in modeling snowpack and runoff is important for improving hydro- logic predictions from seasonal to century timescales with regard to a global model.

The organization of the present study is as follows. In Sect. 2 we describe CCSM4 with a brief discussion of the incorporation of the improved 3-D parameterization for surface solar radiation over mountain surfaces, followed by a discussion in Sect. 3 of the significance of the 3-D radiation effect on the seasonal and elevation-dependent variations in solar flux, sensible and latent heat fluxes, surface temperature, and surface hydrology, including precipitation, snow water equivalent (SWE), and runoff, as well as a discussion of the potential impact of the 3-D parameterization of surface solar radiation on vegetation. Concluding remarks are made in Sect. 4.

\section{3-D radiation parameterization in CCSM4}

To study the long-term effect of the 3-D mountain radiation effect over mountains and snow on the surface energy and hydrology, simulations using CCSM4 have been performed. CCSM is a general circulation model developed by the National Center for Atmospheric Research (NCAR). The fourth version CCSM4 (Gent et al., 2011) is composed of atmosphere (Community Atmosphere Model, CAM4), land (Community Land Model, CLM4), sea ice (Community Ice Code, CICE4), and ocean (Parallel Ocean Program, POP2). A detailed description of CCSM4 has already been given in Gent et al. (2011); thus only a brief outline of the components relevant to our study is presented here. Compared to the previous version, CAM4 uses a finite-volume dynamical core (Lin, 2004) with the revised deep convection parameterization developed by Neale et al. (2008) that includes convective momentum transport. CLM4 was substantially modified (Lawrence et al., 2011) to include a carbon-nitrogen cycle (CLM-CN), the Snow and Ice Aerosol Radiation model (SNICAR; Flanner and Zender, 2006), and a dynamic vegetation model.

To investigate the impact of complex topography on surface solar radiation, the parameterization developed by Lee et al. $(2011,2013)$ has been incorporated into CCSM4. We have carried out 6-year simulations at a horizontal resolution of $0.23^{\circ} \times 0.31^{\circ}$, with prescribed sea surface temperatures and sea ice, greenhouse gases, and aerosols corresponding to the year 2000. The carbon-nitrogen cycle in CLM4 has also been activated. Although our goal is not to investigate 3-D mountain effects on vegetation, which would require long-term simulations to simulate vegetation response to different climate forcings, we included the carbon-nitrogen cycle in our simulations to provide preliminary indications of how vegetation processes may respond to changes in solar radiation due to mountain topography. Since a global high-resolution initial condition for CLM-CN is not available, our simulations were initialized using arbitrary initial conditions of land surface and vegetation states. Hence, we note the caveat that 
slow processes such as the development of the groundwater table and carbon and nitrogen pools in our 6-year-long simulations are far from reaching an equilibrium state and will have some influence on our results even with our focus on comparing simulations with and without 3 -D mountain effects.

We have designed two experiments as follows: the PP experiment is the control run with a default plane-parallel radiative transfer scheme, while the 3-D experiment is identical to the PP experiment, except that the parameterization for 3-D solar flux is implemented. In this study, we focus on a domain covering the Rocky Mountains and the Sierra Nevada from $120-105^{\circ} \mathrm{W}$ to $35-45^{\circ} \mathrm{N}$. Figure 1 displays the elevation map of the western United States at a $0.23^{\circ} \times 0.31^{\circ}$ resolution, and the box is the area for which the spatial average is calculated (see Liou et al., 2013).

In the previous WRF studies of 3-D radiative transfer, surface topography with a $1 \mathrm{~km}$ resolution was used, which was taken from the HYDRO1k geographic database available from the USGS National Center for Earth Resources Observation and Science Data Center. We have since updated the surface topography data using the Shuttle Radar Topography Mission (SRTM) global data set at a resolution of $90 \mathrm{~m}$ (Jarvis et al., 2008) to perform 3-D Monte Carlo photon tracing simulations to improve parameterization accuracy (Lee et al., 2013). Because SRTM data cover the land surface between $56^{\circ} \mathrm{S}$ and $60^{\circ} \mathrm{N}$, the parameterization is applied to all areas within this range. Moreover, Lee et al. (2013) have shown that the parameterization can be applied to any grid box with a size larger than $10 \times 10 \mathrm{~km}$. Therefore, it is suitable for CCSM4 at a quarter-degree resolution.

In addition, we have also accounted for the adjustment involving upward-flux deviations in the parameterization for the application to climate models. It should be noted that the parameterization in our previous studies only adjusts downward solar fluxes calculated by the conventional radiative transfer scheme in a weather or climate model, while the upward fluxes remain unchanged. The impact of upward-flux adjustment is normally insignificant and can be neglected in regional model simulations since the contribution from the upward solar flux, which is only a fraction of the downward flux associated with surface albedo, to the atmospheric heating rate is much smaller than the downward flux. This slight adjustment for upward fluxes will ensure the total energy balance at the surface for simulations involving a 3-D radiative transfer parameterization is obtained in a global model. Specifically, in the structure of a global climate model, the land surface model computes the surface albedo, taking into account land types, snow cover, soil moisture, and other factors. This albedo is then employed as a boundary condition in the global climate model for radiative transfer calculations. We can use the parameterization for 3-D radiative transfer to adjust the land surface albedo, i.e. the ratio of the upward flux to the downward flux, such that the downward flux adjustment remains unchanged. In this manner, a balance of

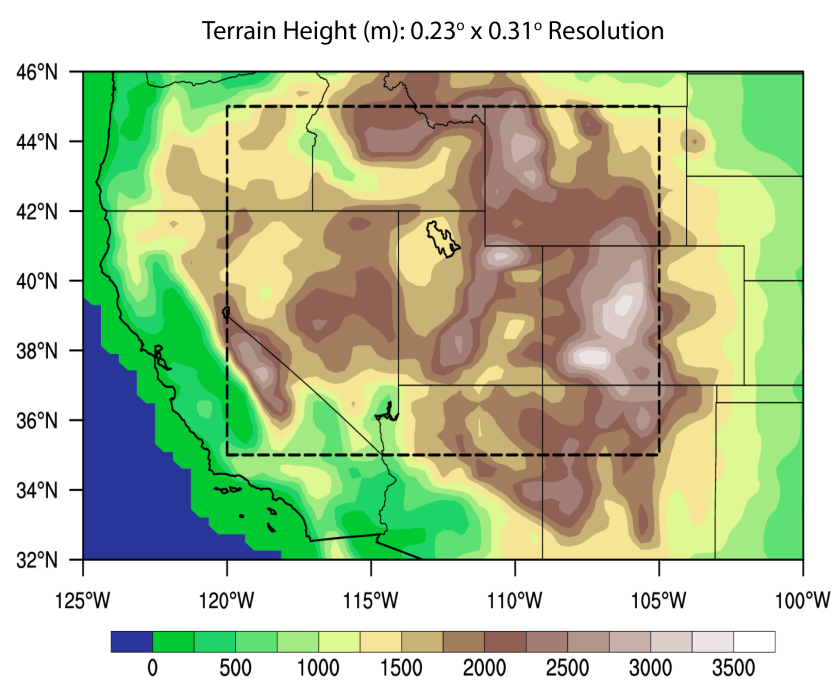

Figure 1. The elevation map over a $0.23^{\circ} \times 0.31^{\circ}$ resolution grid for the Rocky-Sierra areas in the western United States. The box on the map displays major mountainous areas for which simulation results are analyzed and presented in the paper.

the total energy flux at the surface would be ensured, which is critical for long-term climate simulations.

Following Lee et al. (2011), the downward surface solar flux can be categorized as follows: $(1)$ the direct flux $\left(F_{\text {dir }}\right)$ is composed of photons traveling from the Sun to the surface without encountering reflection or scattering; (2) the direct reflected flux $\left(F_{\text {rdir }}\right)$ is the reflection of $F_{\text {dir }}$; (3) the diffuse flux $\left(F_{\text {dif }}\right)$ is associated with photons experiencing single and/or multiple scattering; (4) the diffuse reflected flux ( $\left.F_{\text {rdif }}\right)$ is the reflection of $F_{\text {dif }} ;(5)$ the coupled flux ( $\left.F_{\text {coup }}\right)$ consists of photons encountering multiple reflections. The components related to downward direct solar radiation received by the real topography, $F_{\text {dir }}$ and $F_{\text {rdir }}$, can be expressed as

$F_{\text {dir }}=\left(1+f_{\text {dir }}\right) \hat{F}_{\text {dir }}$ and $F_{\text {rdir }}=f_{\text {rdir }} \hat{F}_{\text {dir }}$,

where $\hat{F}_{\text {dir }}$ is the direct downward solar flux calculated by a plane-parallel radiative transfer scheme. $f_{\text {dir }}$ and $f_{\text {rdir }}$ are the relative deviations evaluated by parameterization and are functions of solar incident angle, standard deviation of elevation within a model grid box, sky view factor (the fraction of sky visible to the target), and terrain configuration factor (the area of surrounding mountains seen by the target). $F_{\text {rdir }}$ is assumed to be proportional to the direct downward surface solar flux because conventional plane-parallel radiative transfer schemes do not explicitly calculate reflected fluxes. With the surface albedo for direct fluxes, $\alpha_{\text {dir }}$, calculated by the land model, the direct radiation absorbed by the surface is equal to $\left(F_{\text {dir }}+F_{\text {rdir }}\right) \times\left(1-\alpha_{\text {dir }}\right)$. We can now introduce the adjusted albedo for direct radiation in mountains, denoted by $\alpha_{\text {dir }}^{\prime}$. To keep the solar radiation absorbed by the surface unchanged, we must have 

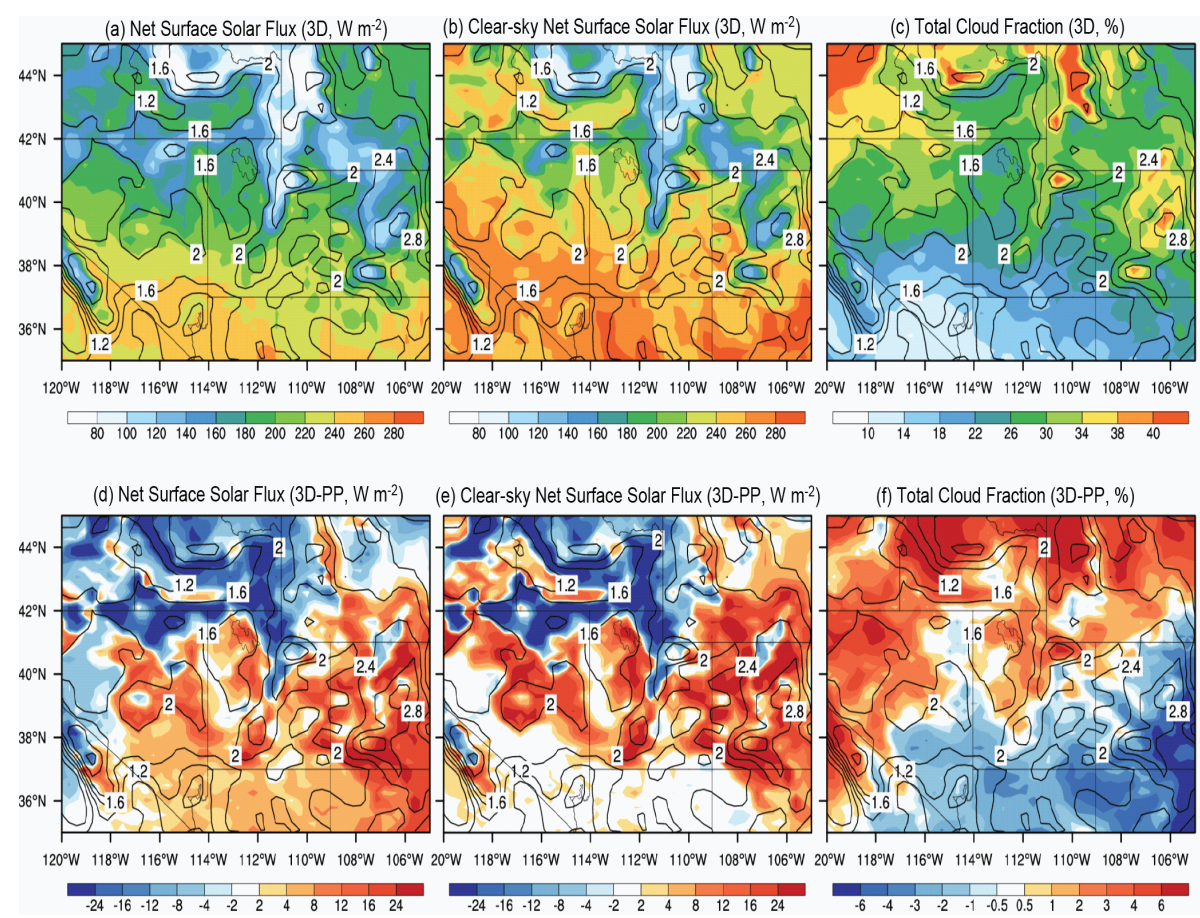

Figure 2. The April mean (a) net surface solar flux $\left(\mathrm{W} \mathrm{m}^{-2}\right)$, (b) clear-sky net surface solar flux $\left(\mathrm{W} \mathrm{m}^{-2}\right)$, and (c) total cloud fraction simulated for the 3-D case, and differences (3-D-PP) in (d) net surface solar flux, (e) clear-sky net surface solar flux, and (f) total cloud fraction.

$\hat{F}_{\text {dir }}\left(1-\alpha_{\text {dir }}^{\prime}\right)=\left(F_{\text {dir }}+F_{\text {rdir }}\right)\left(1-\alpha_{\text {dir }}\right)$.

Substituting Eq. (1) into Eq. (2) leads to

$\alpha_{\text {dir }}^{\prime}=1-\left(1+f_{\text {dir }}+f_{\text {rdir }}\right)\left(1-\alpha_{\text {dir }}\right)$.

Therefore, given the surface albedo provided by the land model and $f_{\text {dir }}$ and $f_{\text {rdir }}$ defined by the original parameterization, the adjusted albedo for direct flux can be obtained. Note that the adjusted albedo is independent of the value of the incoming solar radiation, indicating that it can be calculated first and then used in the plane-parallel radiative transfer scheme to account for the topography effect. Correspondingly, the same procedure can be applied to the diffuse and diffuse reflected fluxes, since CLM4 calculates albedos for direct and diffuse fluxes separately.

\section{Model simulation results}

\subsection{3-D mountain effects on the geographic distribution of energy and hydrology}

As mentioned above, we have conducted two 6-year CCSM4 simulations: PP and 3-D. In the following presentation we have used the results determined from the last 5 years in the analysis. The 5-year mean net surface solar flux (FSNS), clear-sky surface solar flux (FSNSC), and total cloud fraction for April simulated with the incorporation of 3-D parameterization as a function of latitude and longitude are shown in Fig. 2a, b, and c, respectively, where the contour lines represent terrain height $(\mathrm{km})$. FSNS generally follows FSNSC and also depicts a pattern reflecting the negative modulation by the cloud fraction computed from the model. More clouds are generally found over the top of the mountains, where FSNS is relatively smaller because of reflection by snow over highelevation areas. The corresponding deviations (3-D-PP) are displayed in Fig. 2d, e, and f. It reveals that the difference in FSNS is generally dominated by the difference in FSNSC. In this study, FSNSC is controlled by the adjusted albedo, which is related to snow cover and 3-D topography effect. Differences in FSNSC in Fig. 2e are mostly due to changes in the snow field, which will be discussed later. The 3-D topography effect can be found over the Sierra Nevada, where negative/positive deviation appears on the northern/southern slope.

Changes in the surface downward solar flux distribution can affect cloud formation, which in turn will impact the transfer of solar flux reaching the surface. Figure $2 \mathrm{f}$ displays deviations (3-D-PP) of total cloud fraction, which increases over mountain summits in the vicinity of the northern Rockies around $45^{\circ} \mathrm{N}$ and $110^{\circ} \mathrm{W}$ (Fig. 2f) where the downward solar radiation decreases (Fig. 2d). In high-elevation areas, because of more reflection and less shading, the surface gen- 
erally receives more solar radiation in the morning when the sky is clear. The additional insolation due to the topography effect can trigger convection earlier than 1-D simulation, and then the larger cloud fraction produced by including the 3D parameterization can reduce total daily insolation. For the broad south-facing side of the mountains south of $38^{\circ} \mathrm{N}$, increases in surface solar radiation correspond to decreases in cloud fraction.

Figure 3a depicts the monthly mean SWE map for April, simulated from CCSM4 with the inclusion of 3-D radiation parameterization for mountains. Significant SWE is mostly seen over the vast Rocky Mountain region and the narrow Sierra Nevada region. Generally, the SWE pattern shows relatively larger values on the west side of the mountains in response to enhanced precipitation on the windward slopes associated with orographic forcing. However, SWE displays smaller values at the highest elevation and on the east side of mountains in response to the reduced precipitation and the largest solar flux available at mountain tops. Contours of differences (3-D-PP) in the simulated SWE are shown in Fig. 3b. Due to the 3-D mountain effect, SWE generally decreases over mountain tops, especially in the area south of $42^{\circ} \mathrm{N}$. In the Rocky Mountains $\left(\sim 37^{\circ} \mathrm{N}\right.$ and $\left.107^{\circ} \mathrm{W}\right)$, for example, the reduction in SWE is as high as $100 \mathrm{~mm}$ or $40 \%$. Decreased/increased SWE patterns correspond closely to increased/decreased net surface solar radiation patterns, as shown in Fig. 2d.

\subsection{3-D mountain effects on seasonal variation}

Figure 4 shows the 5-year mean deviations (3-D-PP) in the domain-averaged monthly net surface solar flux, sensible heat fluxes, total cloud cover, and surface temperature as a function of month for different elevations over the Sierra Nevada and Rocky Mountain areas. For long-term simulations during which cloud fields are modified through interactions with radiation, cloud feedback can play an important role in radiation field variation. As a matter of fact, the pattern of change in net solar flux is generally the opposite of that of the total cloud fraction, where increases/decreases in the net solar flux correspond to decreases/increases in cloud cover (Fig. 4a and c). For higher elevations, above $2.5 \mathrm{~km}$, the net solar flux shows positive deviations largely throughout the year, indicating that mountain tops tend to receive enhanced solar radiation due to the 3-D effects. For valley areas with elevations lower than $2 \mathrm{~km}$, while solar fluxes reaching the surface are also generally larger in the 3-D case, the magnitude of the increase is smaller than in higheraltitude regions due to the shading effect, as shown in our short-term WRF simulations for the same region (Liou et al., 2013). However, negative deviations mainly occur during December-January and in June due to increases in total cloud fraction (Fig. 4a and c). 3-D mountain effects lead to the reduction in total cloud fraction for most of the year, except for January and June. Mountain clouds normally develop in

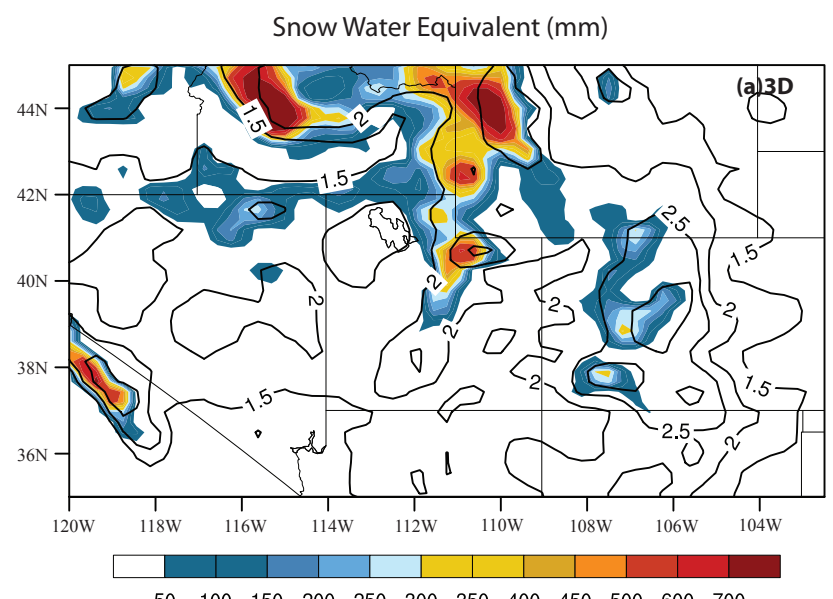

$\begin{array}{llllllllllll}50 & 100 & 150 & 200 & 250 & 300 & 350 & 400 & 450 & 500 & 600 & 700\end{array}$

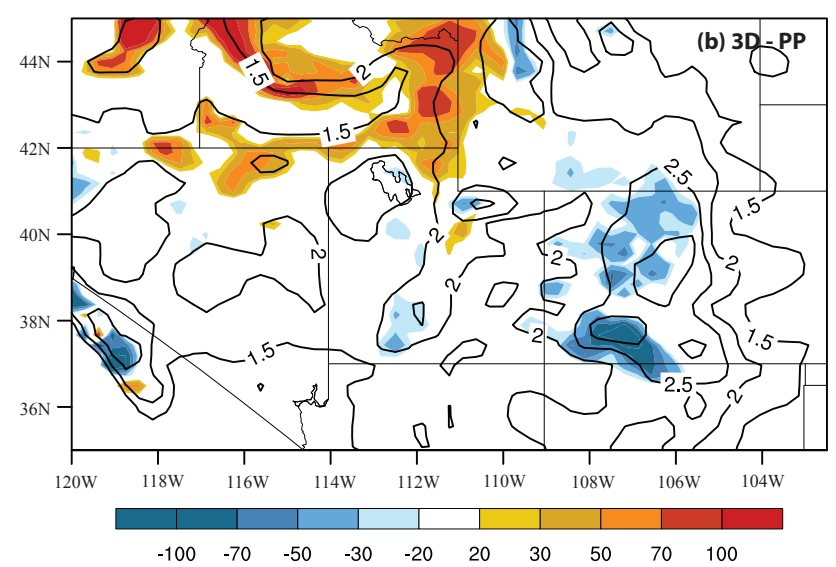

Figure 3. The April mean (a) SWE (mm) and (b) corresponding differences (3-D-PP).

response to surface solar heating, which gradually builds up during the early morning. Furthermore, upslope flows contribute to convection and cloud formation as the elevated surface in mountains heats up relative to the surrounding air. A reduction in surface insolation can therefore reduce upslope flow and convection, leading to reduced clouds. Therefore, the reduced solar insolation in lower elevations due to the 3D mountain effect tends to cool the surface and weaken the convection over mountain regions, resulting in less cloud water. Since cloud formation is primarily dominated by dynamical processes, enhanced surface heating over mountain tops due to the 3-D effect may not be sufficiently large to initiate cloud formation ( $\mathrm{Gu}$ et al., 2012). However, during summer (June), when the surface is heated up, or during winter (January), which is the rainy season over the Sierra Nevada and Rocky Mountains and is associated with frontal systems, additional surface heating from the 3-D mountain effect could enhance cloud formation. Changes in sensible heat flux and surface temperature generally follow the patterns of net solar flux (Fig. 4b and d). 

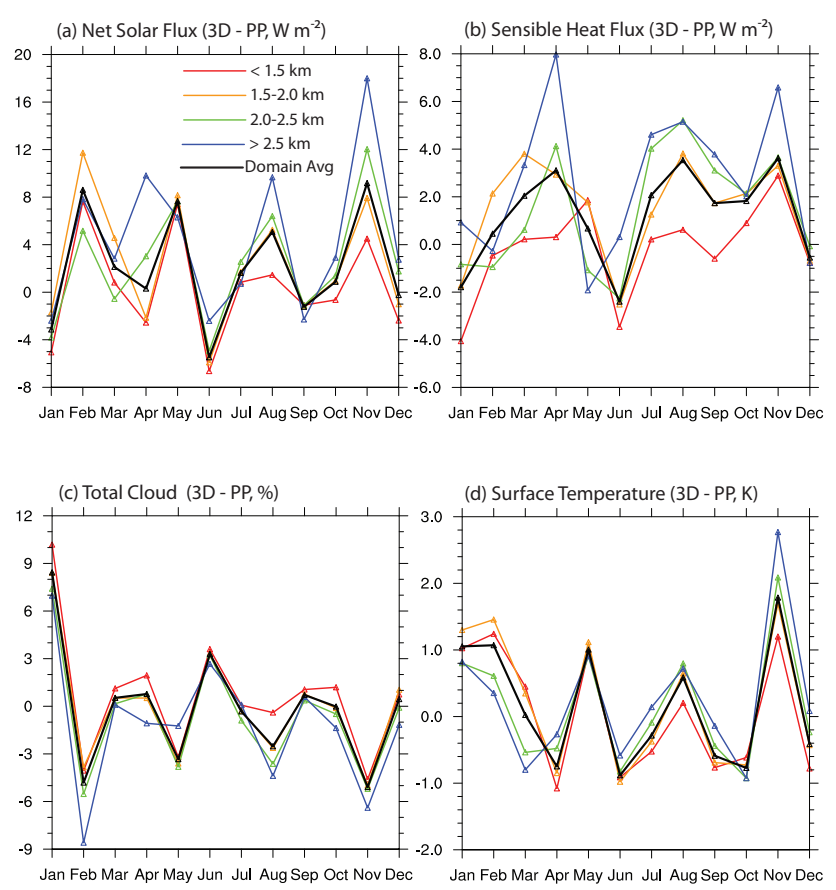

Figure 4. Deviations (3-D-PP) in the domain-averaged monthly (a) net solar flux, (b) sensible heat flux, (c) total cloud fraction, and (d) surface temperature for a 12-month period as a function of elevation lower than $1.5 \mathrm{~km}$ (red), $1.5-2 \mathrm{~km}$ (orange), $2-2.5 \mathrm{~km}$ (green), above $2.5 \mathrm{~km}$ (blue), and for the whole domain (black).

Figure 5 depicts the SWE, precipitation, and liquid runoff for the 3-D experiment and differences between 3-D and PP experiments. It is shown that SWE reaches its maximum in February at lower elevations and in March for higher elevations (Fig. 5a). Due to the 3-D mountain effect, decreases in SWE are found for the higher-elevation zone $(>2.5 \mathrm{~km})$ because more solar radiation is intercepted at mountain tops, while increases are found at lower elevations because of topographic shading (Fig. 5d). Positive deviations become smaller after January because the sun is moving northward and getting closer to the overhead position during spring, leading to a reduced shading effect. The monthly mean precipitation $(\mathrm{mm})$ as a function of elevation over the simulation domain is shown in Fig. 5b. Generally, precipitation increases with elevation due to orographic forcing. Precipitation shows maximum values around July for higher-elevation zones and in January for all elevations in the rainy season (Fig. 5b). Differences in precipitation (Fig. 5e) are mostly negative except in January and follow the pattern of total cloud fraction (Fig. 4c). The liquid runoff reveals a significant increase during April-June for the higher-elevation range associated with the sun's position (Fig. 5c). Differences in liquid runoff are the combined results of snowmelt and precipitation. For higher elevations, due to more solar radiation, runoff first increases during February-March and then decreases after March: this is related to less avail-
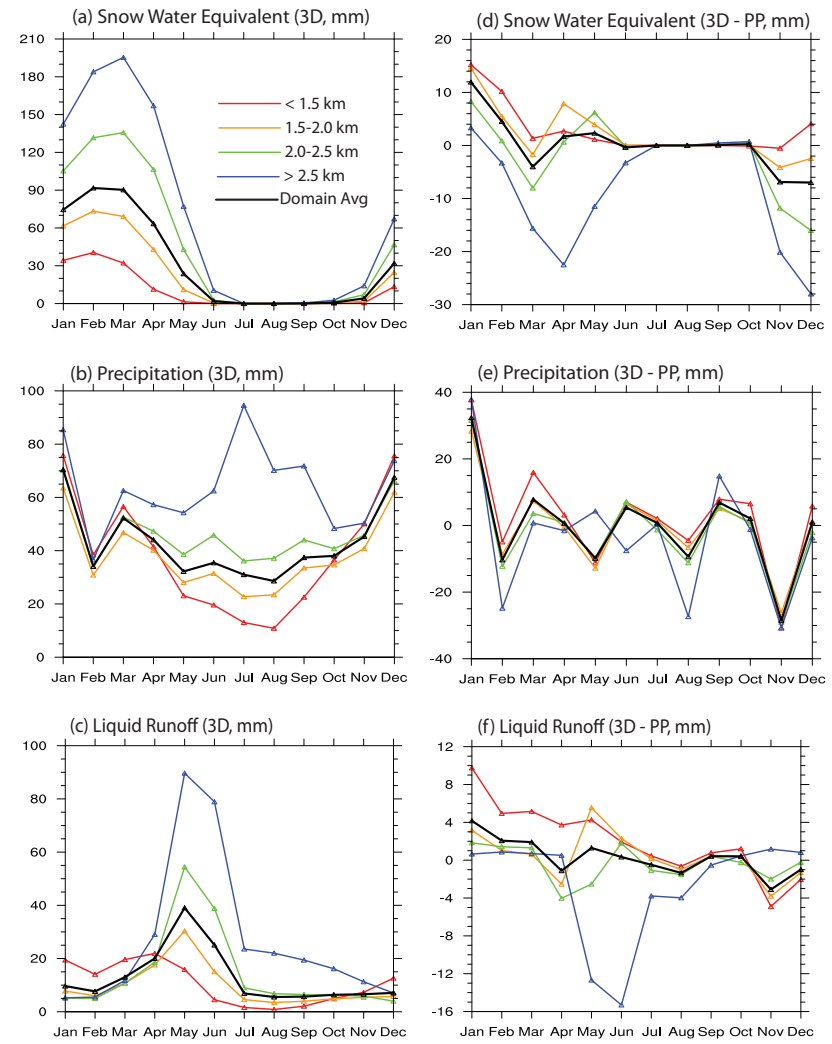

Figure 5. The monthly mean (a) snow water equivalent (SWE, $\mathrm{mm})$, (b) precipitation ( $\mathrm{mm}$ ), and (c) runoff and the corresponding deviations (3-D-PP) in (d) SWE, (e) precipitation, and (f) runoff, averaged over the simulation domain for a 12-month period as a function of elevation lower than $1.5 \mathrm{~km}$ (red), $1.5-2 \mathrm{~km}$ (orange), 2-2.5 km (green), above $2.5 \mathrm{~km}$ (blue), and for the whole domain (black).

able snow and reduced precipitation (Fig. 5f). For valley areas, liquid runoff shows positive deviations beginning in January, associated with more available snow and precipitation. Thus, the impact of the 3-D mountain effect is to speed up snowmelt at mountain tops and at the same time extend snowmelt and snowmelt-driven runoff into the warm season for lower elevations.

3-D mountain effects could have an important impact on surface vegetation. Many plant ecological studies, particularly those performed in mountainous terrain, have revealed that relationships exist between vegetation and the aspect and inclination of slopes (e.g., Killick, 1963; Edwards, 1967; Krueger, 1974; Granger and Schulze, 1977); this relationship results largely from differences in the amounts of light, i.e., solar radiation, intercepted by different slopes. Solar radiation variation has been known to affect not only surface energy budgets (Garnier, 1968) and temperatures but also soil moisture balances and photosynthesis processes. Such topographically induced incoming radiation differences may be regarded as one of the most fundamental variables of the 
plant environment. Over a long-term period, plants would likely respond to differences in light amount (Granger and Schulze, 1977).

Figure 6 illustrates deviations in the domain-averaged monthly net vegetation absorbed solar radiation, sensible heat from vegetation, vegetation temperature, and total leaf area index (LAI) as a function of elevation. It is shown that the 3-D-mountain-induced changes in these vegetationrelated parameters, which will affect the photosynthesis process and vegetation phenology, follow deviation patterns in the surface solar flux produced in part by elevation dependence. For example, for the vegetation-absorbed solar radiation, positive deviations are seen for higher elevations $(>2.5 \mathrm{~km})$, with a maximum value in April, whereas negative deviations are found for valley areas $(<1.5 \mathrm{~km})$, with the largest reduction occurring in January (Fig. 6a); this largely follows the net surface solar flux patterns as shown in Fig. 4a. While the global radiation budget at the top of the atmosphere and surface, precipitation, and surface temperature do not have significant interannual variation, large fluctuations are seen in the temporal evolution of LAI over the western United States. Clearly the vegetation results obtained from a 5 -year simulation have not reached equilibrium as biomass continues to build up after model initialization. Still, it is interesting to see how the difference in LAI between 3-D and PP varies over the seasonal cycle with larger differences developing in early summer (Fig. 6d), following larger changes in the solar flux absorbed by the vegetation (Fig. 6a). However, much longer simulations with spun-up carbon and nitrogen pools will be needed to obtain meaningful results for a vegetation response to mountain-radiation interactions, a subject requiring further investigations with regard to the 3$D$ mountain effects on radiation and vegetation interaction and feedback.

\section{Concluding remarks}

The 3-D radiative transfer parameterization developed for the computation of surface solar fluxes has been incorporated into CCSM4 and applied at a resolution of $0.23^{\circ} \times 0.31^{\circ}$ over the Rocky Mountains and the Sierra Nevada in the western United States. We have carried out 6-year simulations with prescribed SST (sea surface temperature) to understand the long-term effect of 3-D mountains on the monthly variation of surface radiative and heat fluxes and the consequence of snowmelt and precipitation at different elevations.

3-D mountain effects play an important role in the distribution of energy and water sources. Significant increases in net surface solar radiation are mainly found over mountain tops, while reductions, on the other hand, are mostly observed over valley areas. Changes in the surface downward solar flux distribution can affect the clouds and snow fields, which, in turn, will impact the transfer of solar flux reaching the surface. As a result, increases/decreases in surface
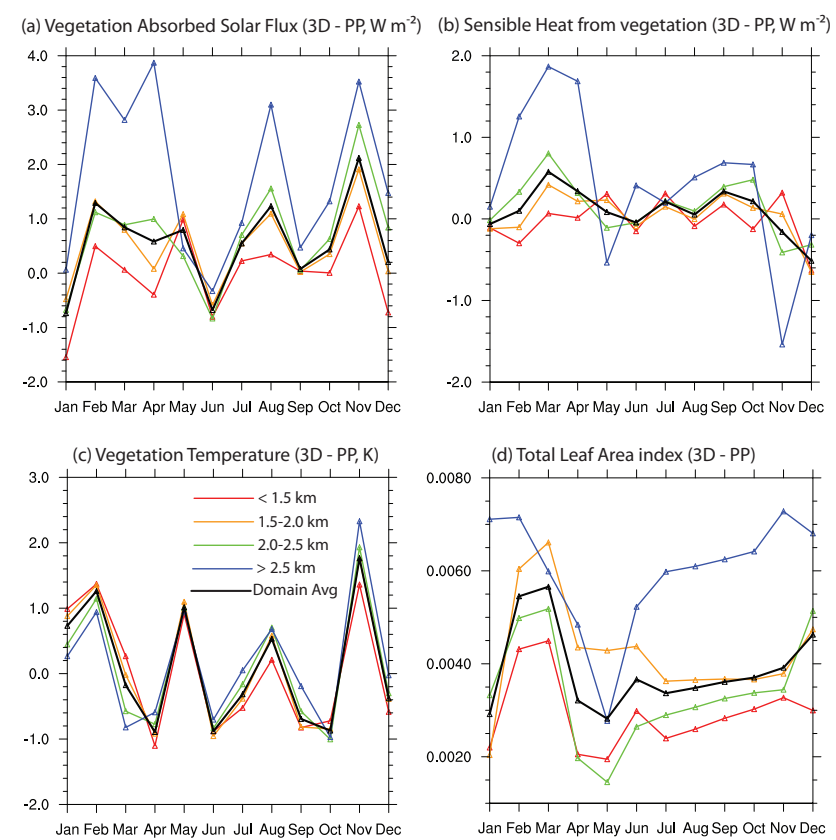

Figure 6. Deviations (3-D-PP) in the domain-averaged monthly (a) vegetation absorbed solar flux, (b) sensible heat flux from vegetation, (c) vegetation temperature, and (d) total leaf area index for a 12 -month period as a function of elevation lower than $1.5 \mathrm{~km}$ (red), $1.5-2 \mathrm{~km}$ (orange), $2-2.5 \mathrm{~km}$ (green), above $2.5 \mathrm{~km}$ (blue), and for the whole domain (black).

solar radiation generally correspond to decreases/increases in cloud fraction and snow amount. Changes in clouds are mostly negative throughout the year due to the reduced solar radiation reaching the surface of lower elevations. The enhanced surface insolation at mountain tops appears to assist cloud formation during summer (June), related to surface heating, or in January, associated with frontal systems. Deviations in the surface solar radiation field can significantly alter the distribution of mountain snow. Decreases/increases in SWE correspond closely to increases/decreases in net surface solar radiation.

3-D mountain features also affect the seasonal variation of surface fluxes and hydrology. Deviations in the monthly mean surface solar flux produced by 3-D mountain effects, as compared to PP results, over the Rocky Mountain and the Sierra Nevada regions are a function of elevation and, at the same time, modulated by cloud feedback. Deviations in the net solar flux show opposite patterns to changes in the total cloud fraction. Deviations in the surface solar radiation field can affect heat fluxes, while changes in the surface energy balance are reflected in surface temperature variation. Changes in heat flux and surface temperature generally follow the deviation patterns in the net surface solar flux. Due to the 3-D mountain effect, decreases in SWE are found at higher-elevation zones as a result of more solar radiation 
intercepted at mountain tops, while increases are found at lower elevations.

Differences in precipitation are mostly negative throughout the year, except in January; these differences follow the patterns of total cloud fraction. Differences in liquid runoff are produced by the combined results from snowmelt and precipitation. For higher elevations, due to increased solar radiation, runoff first increases during February and March but then decreases after March and is associated with reduced snow and precipitation. For valley areas, liquid runoff shows positive deviations after January, associated with more available snow. Therefore, one of the important impacts of the 3-D mountain effect is to speed up the snowmelt at mountain tops while extending snowmelt and snowmelt-driven runoff into the warm season for lower elevations.

Finally, we wish to note that compared to our previous WRF studies of 3-D radiative transfer over mountains (Liou et al., 2013), similar 3-D mountain effects have been manifested in CCSM4 global simulations. Additionally, longterm simulations show that cloud feedback through cloudradiation interactions exerts an important impact on surface fluxes and hydrology.

Acknowledgements. This research was supported by the Ministry of Science and Technology of Taiwan under contracts NSC-1002119-M-001-029-MY5 and NSC-102-2111-M-001-009 and by the Office of Science of the US Department of Energy as part of the Earth System Modeling program through DOE Grant DESC0006742 to UCLA and separate funding to PNNL. PNNL is operated for DOE by Battelle Memorial Institute under contract DE-AC05-76RLO1830.

Edited by: B. Mayer

\section{References}

Bonan, G. B.: Ecological Climatology: Concepts and Applications, Cambridge Univ. Press, New York, USA, 678 pp., 2002.

Edwards, D.: A plant ecology survey of the Tugela Basin, Natal Town \& Regional Planning Commission report No. 10, Pietermaritzburg, 285 pp., 1967.

Flanner, M. G. and Zender, C. S.: Linking snowpack microphysics and albedo evolution, J. Geophys. Res., 111, D12208, doi:10.1029/2005JD006834, 2006.

$\mathrm{Fu}, \mathrm{Q}$. and Liou, K. N.: On the correlated $k$-distribution method for radiative transfer in nonhomogeneous atmospheres, J. Atmos. Sci., 49, 2139-2156, 1992.

Fu, Q. and Liou, K. N.: Parameterization of the radiative properties of cirrus clouds, J. Atmos. Sci., 50, 2008-2025, 1993.

Garnier, B. J.: Estimating the topographic variation of direct radiation: a contribution to geographical microclimateology, Canad. Georgr., 12, 241-248, 1968.

Geiger, R.: The Climate Near the Ground, Harvard Univ. Press, Cambridge, USA, 611 pp., 1965.

Gent, P. R., Danabasoglu, G., Donner, L. J., Holland, M. M., Hunke, E. C., Jayne, S. R., Lawrence, D. M., Neale, R. B., Rasch, P. J.,
Vertenstein, M., Worley, P. H., Yang, Z.-L., and Zhang, M.: The Community Climate System Model, version 4, J. Climate, 24, 4973-4991, 2011.

Granger, J. E. and Schulze, R. E.: Incoming solar radiation patterns and vegetation response: examples from Natal Drakensberg, Vegetation, 35, 47-54, 1977.

Gu, L., Baldocchi, D., Verma, S. B., Black, T. A., Vesala, T., Falge, E. M., and Dowty, P. R.: Advantages of diffuse radiation for terrestrial eco-system productivity, J. Geophys. Res., 107, 4050, doi:10.1029/2001JD001242, 2002.

Gu, Y., Liou, K. N., Chen, W., and Liao, H.: Direct climate effect of black carbon in China and its impact on dust storms, J. Geophys. Res., 115, D00K14, doi:10.1029/2009JD013427, 2010.

Gu, Y., Liou, K. N., Ou, S. C., and Fovell, R.: Cirrus cloud simulations using WRF with improved radiation parameterization and increased vertical resolution, J. Geophys. Res., 116, doi:10.1029/2010JD014574, 2011.

Gu, Y., Liou, K. N., Lee, W.-L., and Leung, L. R.: Simulating 3-D radiative transfer effects over the Sierra Nevada Mountains using WRF, Atmos. Chem. Phys., 12, 9965-9976, doi:10.5194/acp-129965-2012, 2012.

Jarvis, A., Reuter, H. I., Nelson, A., and Guevara, E.: Hole-Filled Seamless SRTM Data (online) V4, International Centre for Tropical Agriculture (CIAT), 2008.

Kapnick, S. and Hall, A.: Observed climate-snowpack relationships in California and their implications for the Future, J. Climate, 23, 3446-3456, 2010.

Kapnick, S. and Hall, A.: Causes of recent changes in western North American snowpack, Clim. Dynam., 38, 1885-1899, doi:10.1007/s00382-011-1089-y, 2012.

Killick, D. J. B.: An account of plant ecology of the cathedral peak area of the Natal Drakensberg, Bot. Sur. Mem., 34, Botanic Res. Institute, Pretoria, 178 pp., 1963.

Krueger, F. J.: The physiography and plant communities of the Jakkalsrivier Catchment, MSc Thesis, University of Stellenbosch, 167 pp., 1974.

Lawrence, D. M., Oleson, K. W., Flanner, M. G., Thornton, P. E., Swenson, S. C., Lawrence, P. J., Zeng, X., Yang, Z.-L., Levis, S., Sakaguchi, K., Bonan, G. B., and Slater, A. G.: Parameterization improvements and functional and structural advances in version 4 of the Community Land Model, J. Adv. Model. Earth Syst., 3, M03001, doi:10.1029/2011MS000045, 2011.

Lee, W.-L., Liou, K. N., and Hall, A.: Parameterization of solar fluxes over mountain surfaces for application to climate models, J. Geophys. Res., 116, D01101, doi:10.1029/2010JD014722, 2011.

Lee, W.-L., Liou, K. N., and Wang, C.-C.: Impact of 3-D topography on surface radiation budget over the Tibetan Plateau. Theor. Appl. Climatol., 113, 95-103, doi:10.1007/s00704-012-0767-y, 2013.

Leung, L. R., Qian, Y., and Bian, X.: Hydroclimate of the western United States based on observations and regional climate simulation of 1981-2000. Part I: Seasonal statistics, J. Climate, 16, 1892-1991, 2003a.

Leung, L. R., Qian, Y., Bian, X., and Hunt, A.: Hydroclimate of the western United States based on observations and regional climate simulation of 1981-2000. Part II: Mesoscale ENSO anomalies, J. Climate, 16, 1912-1928, 2003b. 
Leung, L. R., Qian, Y., Bian, X., Washington, W. M., Han, J., and Roads, J. O.: Mid-century ensemble regional climate change scenarios for the western United States, Climatic Change, 62, 75113, 2004.

Lin, S. J.: A “vertically Lagrangian" finite-volume dynamical core for global models, Mon. Weather Rev., 132, 2293-2307, 2004.

Liou, K. N., Lee, W.-L., and Hall, A.: Radiative transfer in mountains: Application to the Tibetan Plateau, Geophys. Res. Lett., 34, L23809, doi:10.1029/2007GL031762, 2007.

Liou, K. N., Gu, Y., Leung, L. R., Lee, W. L., and Fovell, R. G.: A WRF simulation of the impact of 3-D radiative transfer on surface hydrology over the Rocky Mountains and Sierra Nevada, Atmos. Chem. Phys., 13, 11709-11721, doi:10.5194/acp-1311709-2013, 2013.
McCabe, G. J. and Clark, M. P.: Trends and variability in snowmelt runoff in the Western United States, J. Hydrol., 6, 476-482, 2005.

Mote, P., Salathe, E., and Jump, E.: Scenarios of future climate for the Pacific Northwest, A report prepared by the Climate Impacts Group (Center for Science in the Earth System, University of Washington, Seattle), 2007.

Müller, M. D. and Scherer, D.: A grid- and subgrid-scale radiation parameterization of topographic effects for mesoscale weather forecast models, Mon. Weather Rev., 133, 1431-1442, 2005.

Neale, R. B., Richter, J. H., and Jochum M.: The impact of convection on ENSO: From a delayed oscillator to a series of events. J. Climate, 21, 5904-5924, 2008. 